\title{
Effect of a bispidinone analog on mitochondria-mediated apoptosis in HeLa cells
}

\author{
MYEONGJIN YI $^{1}$, PARAMASIVAM PARTHIBAN $^{1}$, JIYOUNG HWANG $^{1}$, XIN ZHANG $^{1,2}$, \\ HYUNJIN JEONG $^{1}$, DONG HO PARK ${ }^{1}$ and DONG-KYOO KIM ${ }^{1}$
}

\author{
${ }^{1}$ Department of Chemistry and Institute of Basic Sciences, Inje University, Gimhae 621-749, Republic of Korea; \\ ${ }^{2}$ School of Life Science and Biopharmaceutics, Shenyang Pharmaceutical University, Shenyang 110016, P.R. China
}

Received August 8, 2013; Accepted October 4, 2013

DOI: $10.3892 /$ ijo.2013.2162

\begin{abstract}
The present study was carried out to investigate the effect of 2,4,6,8-tetraaryl-3,7-diazabicyclo[3.3.1]nonan-9-one (bispidinone) analogs on the in vitro growth of human cervical carcinoma (HeLa) cells. A series of 11 bispidinone analogs was synthesized with substituents, e.g., fluoro/methyl/ethyl/isopropyl/ thiomethyl/methoxy groups, at various positions. These compounds were synthesized to identify which substituent and position induced the strongest cytotoxic effect in cancer cells. Among these synthetics, analog 9, which contains methoxy groups, had the most significant cytotoxic effect on HeLa cells, and its $\mathrm{IC}_{50}$ value was less than $13 \mu \mathrm{M}$. A WST- 8 assay also showed that analog 9 inhibited the proliferation of HeLa cells. By using DNA content analysis, we found that analog 9 induced sub-G1 and G1 phase arrest in a time-dependent manner. A $\left[{ }^{3} \mathrm{H}\right]$-thymidine incorporation assay suggested that analog 9 inhibited DNA replication in HeLa cells. On performing light microscopy, morphological changes such as cellular shrinkage and disruption, which are apoptotic features, were observed in HeLa cells. Annexin V/propidium iodide double staining and rhodamine-123 staining showed that analog 9 induced apoptosis and disrupted the intracellular mitochondrial membrane potential in HeLa cells. The western blot analysis results suggested that analog 9 induced mitochondria-mediated apoptosis. In addition, we have shown that analog 9 may play a role in the Fas signaling apoptotic pathway.
\end{abstract}

\section{Introduction}

The stereochemistry and synthesis of 3,7-diazabicyclo[3.3.1] nonan-9-ones (bispidines) are of interest owing to the biological importance of these substances (1). Conformational analysis of

Correspondence to: Professor Dong-Kyoo Kim, Department of Chemistry and Institute of Basic Science, Inje University, 607 Aubang-dong, Gimhae 621-749, Republic of Korea

E-mail: chemkdg@inje.ac.kr

Key words: bispidinone, apoptosis, the mitochondria-dependent mediated pathway, mitochondrial membrane potential bispidines is also of interest from a theoretical view point and, in particular, 2,4,6,8-tetraaryl-3,7-diazabicyclo[3.3.1]nonan9-one (bispidinone) constitutes an interesting case for research owing to the presence of 4 aryl groups (2). The preparation and use of bispidines as chelate ligands for radioactive copper isotopes for diagnosis $\left({ }^{64} \mathrm{Cu}\right)$ or therapy $\left({ }^{67} \mathrm{Cu}\right)$ have been studied (3). A bifunctional bispidine derivative can be readily functionalized with biologically active molecules at the pendant carboxylate groups (3). However, the biological properties of bispidinone with regard to the molecular mechanisms of its therapeutic effects on cancer have not been examined. Therefore, we synthesized a series of 11 bispidinone analogs with fluoro/methyl/ethyl/isopropyl/thiomethyl/methoxy substituents at various positions (Fig. 1). Firstly, we undertook a WST-8 assay to identify which substituents and positions generate the strongest cytotoxic effect. 2,4,6,8-Tetrakis(2methoxyphenyl)-3,7-diazabicyclo[3.3.1]nonan-9-one (analog 9) was more cytotoxic in HeLa cells than the other analogs; therefore, this study was undertaken to examine the anticancer activity of analog 9 .

Cancer is caused by the uncontrolled growth of cells, and it has been thought to be the result of interactions between genetic susceptibility and environmental toxins. In the broad sense, most chemotherapeutic drugs work by impairing cell division; however, some cause cancer cells to undergo apoptosis. Many drugs have been developed to treat cancer, although the principles and limitations of chemotherapy founded by the early researchers still apply (4). Therefore, identifying synthetic compounds with anticancer effects is also essential for the treatment of cancer. Recently, the study of apoptosis has been a major focus of cancer research. Apoptosis, i.e., programmed cell death, is highly regulated through the extrinsic and intrinsic pathways $(5,6)$. Apoptosis is characterized by chromatin condensation, DNA fragmentation, membrane blebbing and cell shrinkage (7). The intrinsic pathway is induced by many stimuli, e.g., DNA damage, cellular distress, hypoxia and cytotoxic agents, which act inside cells (6). In recent studies, mitochondria have been suggested to play an important role in apoptosis (8). In response to apoptosis, which is especially related to the intrinsic pathways, some important events occur in the mitochondria. These events can be controlled and regulated by members of the Bcl-2 family (9), which includes anti- and proapoptotic 

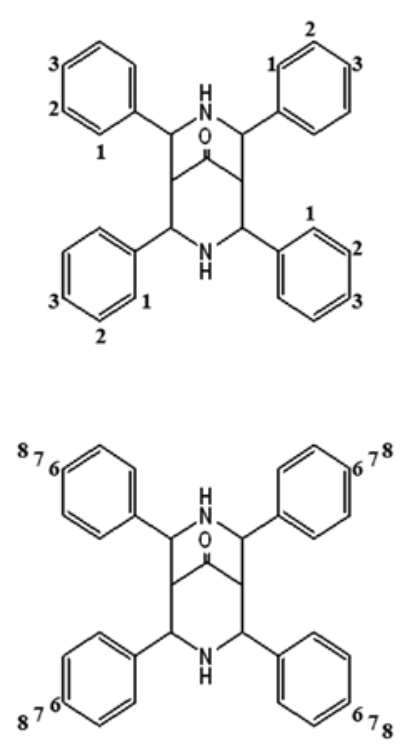<smiles>OC1C2C(c3ccccc3)NC(c3ccccc3)C1C(c1ccccc1)NC2c1ccccc1</smiles><smiles>C1=CC=C2C=C(C=C1)C1(c3ccccc3)C3C2NC(c2ccccc2)C1C(c1ccccc1)NC3c1ccccc1</smiles>

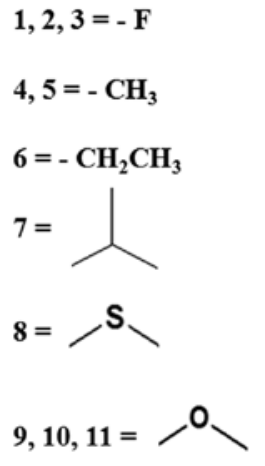

Figure 1. The structures of bispidinone (2,4,6,8-tetraaryl-3,7-diazabicyclo[3.3.1]nonan-9-one) and 11 synthetic analogs. A series of eleven bispidinone analogs were synthesized with fluoro/methyl/ethyl/isopropyl/thiomethyl/methoxy substituents on various positions.

molecules and constitutes a critical intracellular decision point within a common death pathway (10). The presence of the protein Bad counters the antiapoptotic effects of Bcl-xL and $\mathrm{Bcl}-2$, potentially through direct inhibition of their activity or displacement of the proapoptotic protein Bax (11). In the mitochondria-mediated pathway, mitochondria release some apoptotic proteins, including cytochrome $c$, into the cytosol (12). Cytosolic cytochrome $c$ binds to apoptotic protease activation factor 1 (APAF1) to produce active caspase-9 and caspase-3, thereby inducing caspase-dependent apoptosis (13). Caspases (cysteine-aspartic proteases or cysteine-dependent aspartate-directed proteases) are a family of cysteine proteases that regulate and play essential roles in apoptosis in the death receptor- and mitochondria-mediated pathways (14). In the death receptor-mediated pathway, caspase- 8 plays an initiator role and activates the final executioner caspase-3 (15). Apoptosis, via the mitochondria-mediated pathway, also occurs in a caspase-independent manner after the mitochondrial release of apoptosis-inducing factor. It could be translocated to the nucleus for the induction of chromatin condensation and DNA fragmentation (16).

Cell cycle regulation is closely linked to cell proliferation, and one of the most notable features of a tumor is abnormal cell cycle management (17). The G1 phase or post-mitotic phase is a period in the cell cycle during interphase, before the $S$ phase. In many cells, this phase represents the main period of cell growth. During this stage, new organelles are synthesized so that the cells require the production of structural proteins and enzymes, resulting in a high level of protein synthesis and a high rate of metabolism (18).

Emerging evidence has characterized the induction of apoptosis to treat cancer (19-21). The aim of this study was to determine whether analog 9 can exert its activity on cancer cells. In this report, we investigated the anticancer effect of analog 9 to identify whether a novel compound can be an appropriate candidate for an antitumor agent.

\section{Materials and methods}

Chemicals. The propidium iodide (PI)/RNase staining buffer and Annexin V-FITC kit for apoptosis were from BD Biosciences Pharmingen (San Diego, CA, USA). Dimethyl sulfoxide (DMSO) and phosphate-buffered saline (PBS, $\mathrm{pH}$ 7.4) were purchased from Sigma-Aldrich Chemical Co. (St. Louis, MO, USA). Eagle's minimum essential medium (EMEM), fetal bovine serum (FBS), penicillin-streptomycin, and trypsin-EDTA were obtained from HyClone Laboratories, Inc. (Logan, UT, USA). Cell Counting Kit-8 (CCK-8) was purchased from Dojindo Molecular Technologies, Inc. (Osaka, Japan). All other chemicals were of analytical reagent grade. Rhodamine-123 was purchased from Molecular Probes (Eugene, OR, USA).

Cell lines. HeLa cells obtained from the American Type Culture Collection (Manassas, VA, USA) were cultured in EMEM supplemented with $10 \%$ FBS and $1 \%$ penicillinstreptomycin at $37^{\circ} \mathrm{C}\left(5 \% \mathrm{CO}_{2}\right)$ in a humidified atmosphere.

Preparation of bispidinone and its analogs. Bispidinone and its analogs were obtained from the laboratory of D.H.P. and synthesized by P.P. The stock solutions were prepared in DMSO and kept at $4^{\circ} \mathrm{C}$. Further dilutions were made immediately prior to each experiment.

Cell viability and proliferation assays. The effect of the bispidinone analogs on cell viability was investigated in HeLa cells according to the method reported by Tominaga et al (22). We plated $5.0 \times 10^{3}$ cells into each well of a 96 -well microplate. After $24 \mathrm{~h}$, the medium replaced with fresh medium containing the bispidinone analogs at various concentrations $(15,30$ and $60 \mu \mathrm{M})$. The plate was incubated for an additional $48 \mathrm{~h}$. The CCK-8 reagent $(10 \mu \mathrm{l})$ was then added to each well and incubated for $2 \mathrm{~h}$. Cell viability 
was assessed using 2-(2-methoxy-4-nitrophenyl)-3-(4nitrophenyl)-5-(2,4-disulfophenyl)-2H-tetrazolium (WST-8), an indicator that is reduced by the dehydrogenases in cells to give an orange colored product (formazan), which is soluble in cell culture medium. The optical density of living cells was read at $450 \mathrm{~nm}$ using a multimicroplate reader (Synergy HT; BioTek, Winooski, VT, USA). Wells containing cells and an appropriate volume of vehicle (DMSO) served as the control. Wells containing only culture medium and the CCK- 8 reagent served as the blank. The percentage cytotoxicity of analog 9 was calculated according to the following equation: $\%$ cytotoxicity $=[(\mathrm{Ac}-\mathrm{A}) /(\mathrm{Ac}-\mathrm{Ab})] \times 100$, where $\mathrm{Ac}, \mathrm{Ab}$ and A represent the mean optical density of the vehicle control, blank and treated groups, respectively. In order to determine the effect of analog 9 on cell proliferation, $5.0 \times 10^{3}$ cells $/ \mathrm{ml}$ medium were seeded in 96-well plates and treated with or without analog $9(15 \mu \mathrm{M})$ for various durations. Each experiment was repeated at least 3 times.

Cell cycle arrest analysis. The cells $\left(3.0 \times 10^{5}\right.$ cells in a $60-\mathrm{mm}$ dish) treated with or without analog 9 were collected by trypsinization and washed with ice-cold PBS by centrifugation. The cells were suspended in PBS and fixed with 70\% ethanol $(\mathrm{v} / \mathrm{v})$. The samples were then washed with ice-cold PBS and stained with PI/RNase staining buffer for $15 \mathrm{~min}$ at room temperature (23). The cells in different phases of the cell cycle were analyzed using a FACScan flow cytometer, and 20,000 events were analyzed for each sample. The percentage of cells in the different phases of the cell cycle was determined using ModFit software (Becton-Dickinson Instruments, Franklin Lakes, NJ, USA).

Annexin V-FITC/PI apoptotic analysis. Cells $\left(3.0 \times 10^{5}\right.$ cells in a $60-\mathrm{mm}$ dish) treated with or without analog 9 were collected by trypsinization and washed with ice-cold PBS via centrifugation. Then, $1.0 \times 10^{5}$ cells were resuspended in $100 \mu \mathrm{l}$ binding buffer and stained with $5 \mu \mathrm{l}$ Annexin V-FITC and $10 \mu \mathrm{l}$ PI $(50 \mu \mathrm{g} / \mathrm{ml})$ for $15 \mathrm{~min}$ at room temperature in the dark (23). Analysis was performed using a FACSCalibur flow cytometer (Becton-Dickinson, San Jose, CA, USA) with 10,000 events each time. The data were analyzed using Cell Quest Pro software (Becton-Dickinson Instruments).

Measurement of apoptotic cell morphology. HeLa cells were distributed $\left(1.0 \times 10^{5}\right.$ cells/well) into a 24 -well plate and allowed to adhere overnight. The cells were treated with analog $9(15 \mu \mathrm{M})$ for 24 and $48 \mathrm{~h}$. Non-treated wells received an equivalent volume of DMSO $(<0.1 \%)$ as the control. Optic phase-contrast photographs were taken using a Nikon Phase Contrast-2, ELWD 0.3 inverted microscope.

$\left[{ }^{3} \mathrm{H}\right]$-thymidine incorporation assay. The $\left[{ }^{3} \mathrm{H}\right]$-thymidine incorporation assay was performed as described previously (24). Briefly, HeLa cells were cultured in 12-well plates in growth medium (EMEM $+10 \%$ FBS $+1 \%$ penicillin-streptomycin). After the cells had grown to $70-80 \%$ confluence, they were rendered quiescent by incubation for $24 \mathrm{~h}$ in EMEM containing $2 \%$ FBS. Analog $9(15 \mu \mathrm{M})$ in EMEM (or DMSO) supplemented with $10 \%$ FBS was added to the cells and the cultures were incubated for 21 and 45 h. $\left[{ }^{3} \mathrm{H}\right]$-thymidine was added at $1 \mu \mathrm{Ci} / \mathrm{ml}(1 \mu \mathrm{Ci}=37 \mathrm{kBq})$ and incubated for $3 \mathrm{~h}$. Incorporated $\left[{ }^{3} \mathrm{H}\right]$-thymidine was extracted in a cell lysis buffer and measured using a liquid scintillation analyzer (Tri-Carb 2910TR; Perkin-Elmer Inc., Waltham, MA, USA).

Measurement of mitochondrial-membrane potential disruption. Changes in mitochondrial-membrane potential $(\Delta \Psi \mathrm{m})$ were measured using flow cytometry (FACSCalibur; BD Biosciences Pharmingen). HeLa cells treated with analog 9 and untreated control cells were stained with $10 \mu \mathrm{g} / \mathrm{ml}$ rhodamine-123 (Rh-123; Molecular Probes) and incubated at $37^{\circ} \mathrm{C}$ for $30 \mathrm{~min}$. Analysis was performed using a FACSCalibur flow cytometer (Becton-Dickinson) with 10,000 events per sample. The data were analyzed using Cell Quest Pro software (Becton-Dickinson Instruments).

Western blot analysis assay. After the cells were treated with or without analog 9, total cell lysates and cytosolic fractions were prepared as described previously (25). The protein content of the lysates was determined by the Bradford protein assay (Bio-Rad, Hercules, CA, USA). Proteins $(25 \mu \mathrm{g})$ were resolved by sodium dodecyl sulfate-polyacrylamide gel electrophoresis and transferred onto nitrocellulose membranes (Schleicher \& Schuell, Keene, NH, USA) by western blot analysis (26). The following primary polyclonal antibodies were used: Bcl-2, procaspase- 8 , procaspase- 9 and $\beta$-actin (1:1,000; Cell Signaling Technology, Danvers, MA, USA), procaspase-3 and p53 (1:300; Santa Cruz Biotechnology, Santa Cruz, CA, USA), and Bax (1:1,000; BD Biosciences Pharmingen).

Statistical analysis. Each experiment was repeated at least 3 times. Data are expressed as the mean \pm SD values of 3 independent experiments. We performed statistical analysis by one-way analysis of variance. The criterion for significance was set at $\mathrm{P}<0.05$. Microsoft Excel 2007 (Roselle, IL, USA) was used for the statistical and graphical evaluations.

\section{Results}

Effects of analog 9 on the viability and proliferation of $\mathrm{HeLa}$ cells. Initially, we evaluated the cytotoxicity of different concentrations of bispidinone and its analogs against $\mathrm{HeLa}$ cells. The cytotoxic effects of bispidinone compounds were examined in a concentration-dependent manner in HeLa cells using the WST-8 assay (Table I). After incubation of the cells with increasing concentrations $(15,30$, and $60 \mu \mathrm{M}$ ) of bispidinone and 11 analog compounds for $48 \mathrm{~h}$, analog 9 showed a significant cytotoxic effect in a concentration-dependent manner when compared with the control. The other compounds did not show a clear cytotoxic effect. Therefore, we selected analog 9 for further study. The $\mathrm{IC}_{50}$ value of analog 9 was approximately $13 \mu \mathrm{M}$ (Fig. 2A). When HeLa cells were treated with $15 \mu \mathrm{M}$ analog 9 for $0,12,24,36$, 48 and $60 \mathrm{~h}$, their proliferation increased gradually until $48 \mathrm{~h}$ and began to decrease at $60 \mathrm{~h}$, whereas the untreated cells maintained an exponential proliferation state. A significant difference in the absorbance from the control was observed at $60 \mathrm{~h}$, showing that analog 9 inhibited HeLa cell proliferation after 60-h incubation (Fig. 2B). 

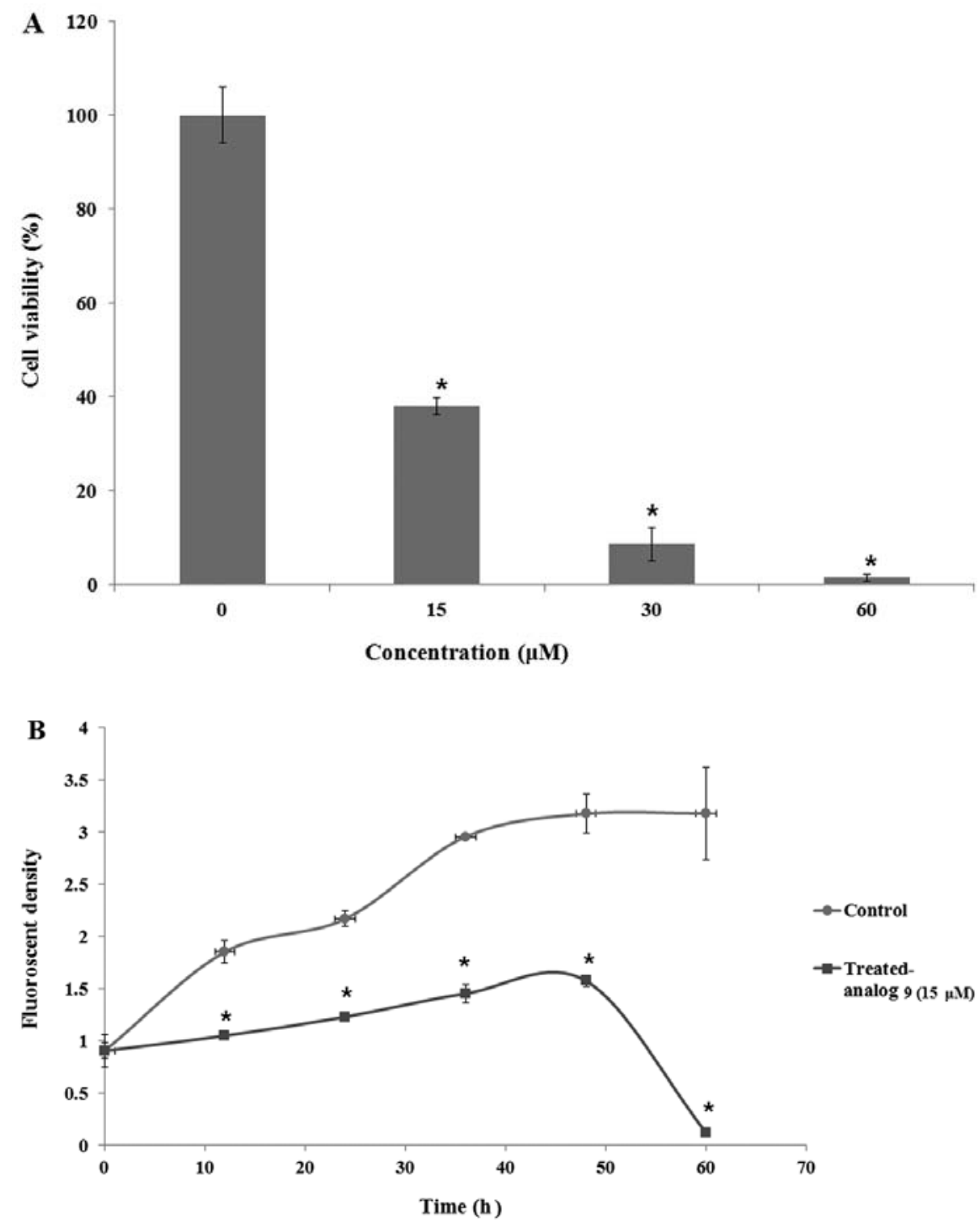

Figure 2. Analog 9 had effects on HeLa cell viability and proliferation. (A) HeLa cells were treated with $0,15,30$ and $60 \mu \mathrm{M}$ of analog 9, respectively, for $48 \mathrm{~h}$. (B) HeLa cells were treated with either vehicle alone or $15 \mu \mathrm{M}$ of analog 9 for $0,12,24,36,48$ and $60 \mathrm{~h}$, respectively. Data were obtained by WST- 8 assay at $450 \mathrm{~nm}$. Results are the mean $\pm \mathrm{SD}, \mathrm{n}=3$. ${ }^{*} \mathrm{P}<0.05$, denotes statistically significant difference vs. the control at the same level.

Table I. Evaluation of cytotoxicity of bispidinone and 11 analogs on HeLa cells.

\begin{tabular}{lc}
\hline Compound & $\mathrm{IC}_{50}$ value \\
\hline Mother compound (MC) & $>100$ \\
Analog 1 & 84.48 \\
Analog 2 & 44.84 \\
Analog 3 & 93.20 \\
Analog 4 & $>100$ \\
Analog 5 & $>100$ \\
Analog 6 & $>100$ \\
Analog 7 & $>100$ \\
Analog 8 & $>100$ \\
Analog 9 & 12.33 \\
Analog 10 & $>100$ \\
Analog 11 & 99.23 \\
\hline
\end{tabular}

Analog 9 induces arrest at the sub-Gl and G1 phases of the cell cycle. The growth and inhibition of cells are mediated by the cell cycle (27). The abnormal regulation of the cell cycle could be an event that initiates apoptosis (28-30). To assess the effect of analog 9 on cell cycle progression, HeLa cells were treated with or without $15 \mu \mathrm{M}$ analog 9 for 24 and $48 \mathrm{~h}$. Treatment with analog 9 (Fig. 3B and D) increased the number of cells in the sub-G1 and G1 phases compared to the untreated cells (Fig. 3A and C). Furthermore, analog 9 increased the number of cells in the G1 phase in a time-dependent manner. Thus, analog 9 induced the arrest of HeLa cells in the sub-G1 and G1 phases of the cell cycle.

Analog 9 induces apoptosis in HeLa cells. An Annexin V-FITC and PI double-staining assay was performed to assess the induction of apoptosis. To evaluate whether analog 9 induced apoptosis, HeLa cells were treated with or without $15 \mu \mathrm{M}$ analog 9 for 24 and $48 \mathrm{~h}$ and then stained with Annexin V-FITC and PI, followed by analysis using flow cytometry. This double- 

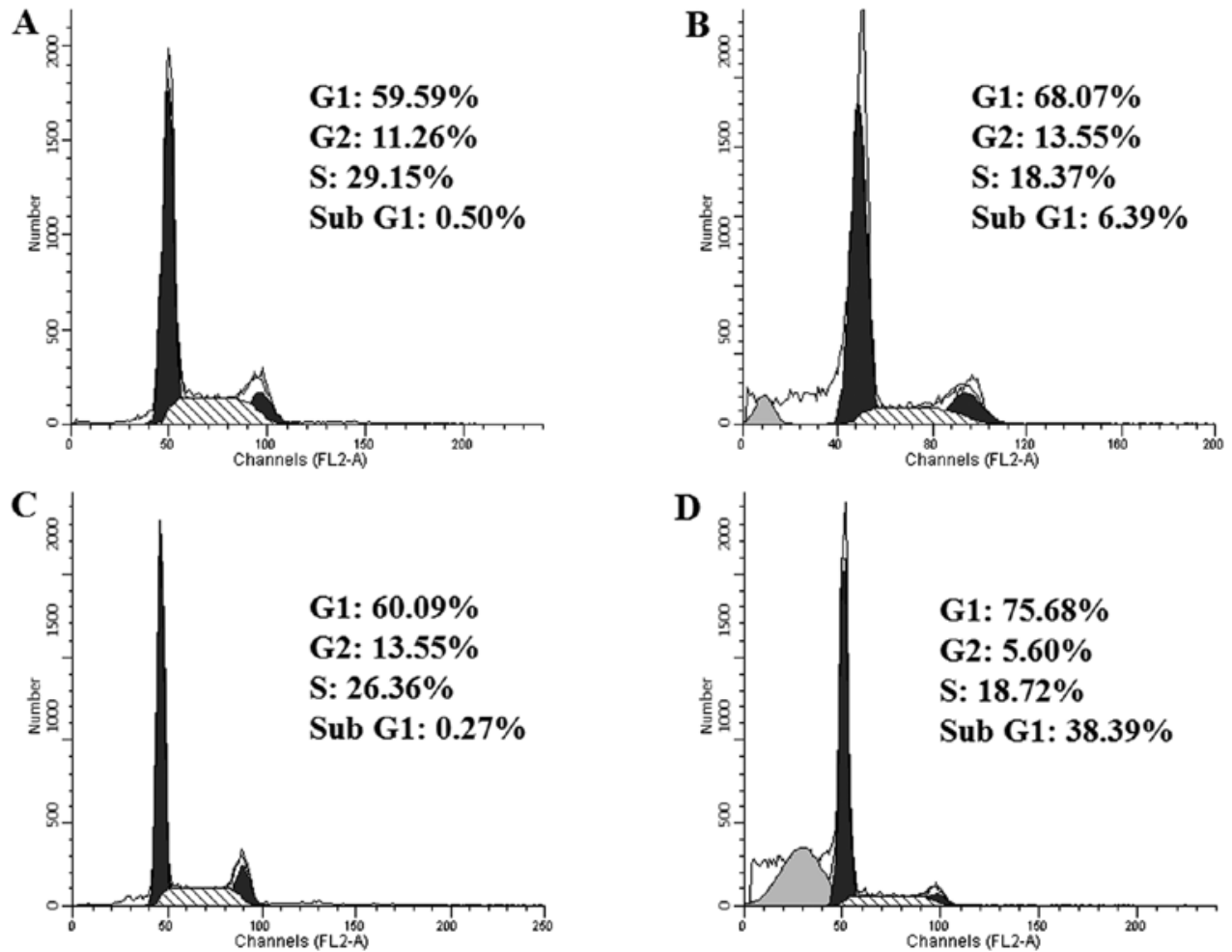

Figure 3. Induction of sub G1 and G1 phases in HeLa cell cycle by analog 9. Untreated analog 9 for (A) 24 and (C) $48 \mathrm{~h}$, respectively. Treatment with $15 \mu \mathrm{M}$ of analog 9 for (B) 24 and (D) 48 h, respectively. Cells were measured by flow cytometry and analyzed by Modfit software (Becton-Dickinson Instruments). All the experiments were performed in triplicate and gave similar results.
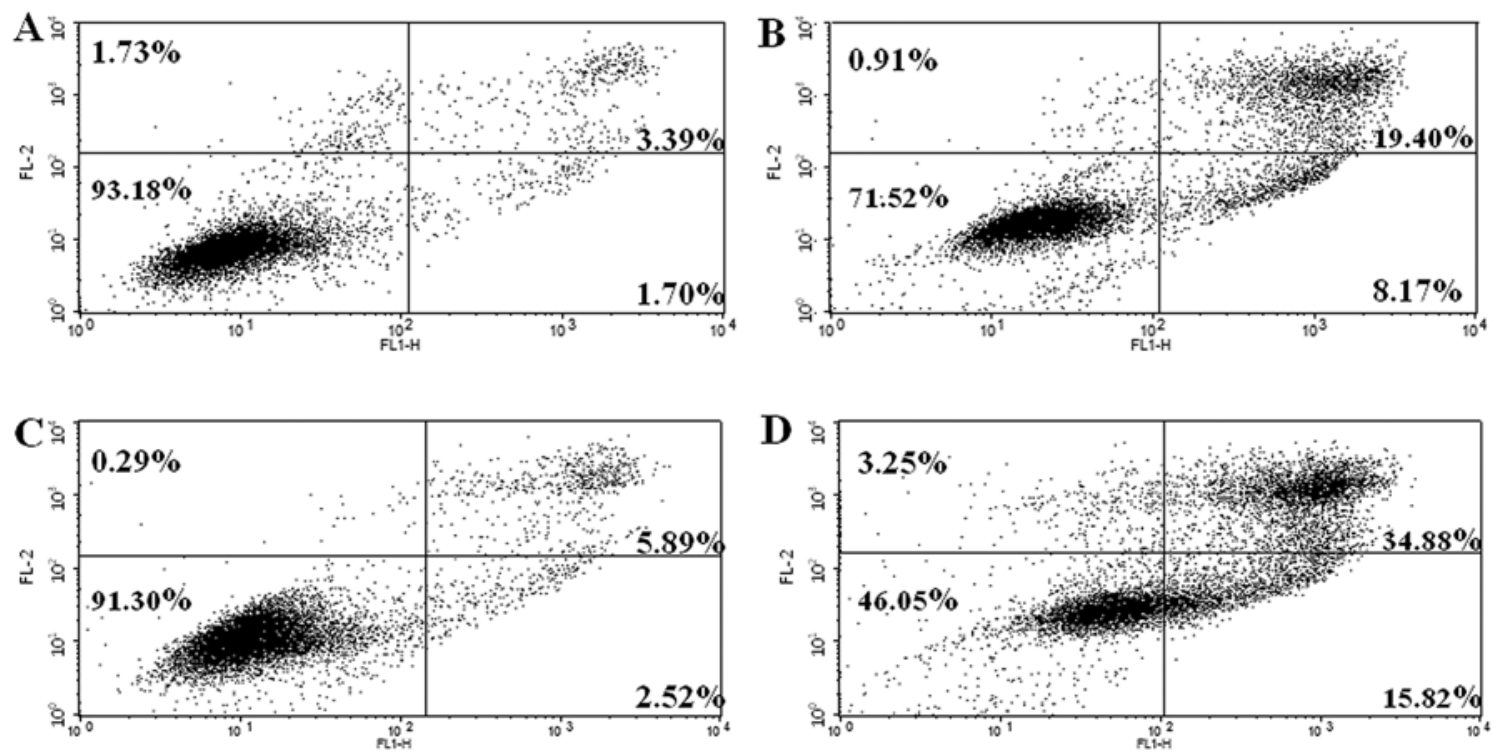

Figure 4. Induction of apoptosis in HeLa cell by analog 9. Untreated analog 9 for (A) 24 and (C) $48 \mathrm{~h}$, respectively. Treatment with $15 \mu \mathrm{M}$ of analog 9 for (B) 24 and (D) $48 \mathrm{~h}$, respectively. Samples were measured by flow cytometry and analyzed by Cell Quest Pro software (Becton-Dickinson Instruments). All the experiments were performed in triplicate and gave similar results.

staining assay allows live non-apoptotic cells (Annexin $\left.\mathrm{V}^{-} / \mathrm{PI}^{-}\right)$to be distinguished from early apoptotic cells (Annexin $\left.\mathrm{V}^{+} / \mathrm{PI}\right)$ and late apoptotic cells (Annexin $\left.\mathrm{V}^{+} / \mathrm{PI}^{+}\right)(31,32)$. As shown in Fig. 4, treatment with analog 9 increased the number of cells undergoing apoptosis (Fig. 4B and D) compared with the untreated cells (Fig. 4A and C). Therefore, these results show that analog 9 induced apoptosis in HeLa cells in a time-dependent manner.

Analog 9 induces morphological changes in HeLa cells. Cell morphological observation reveals important characteristics 

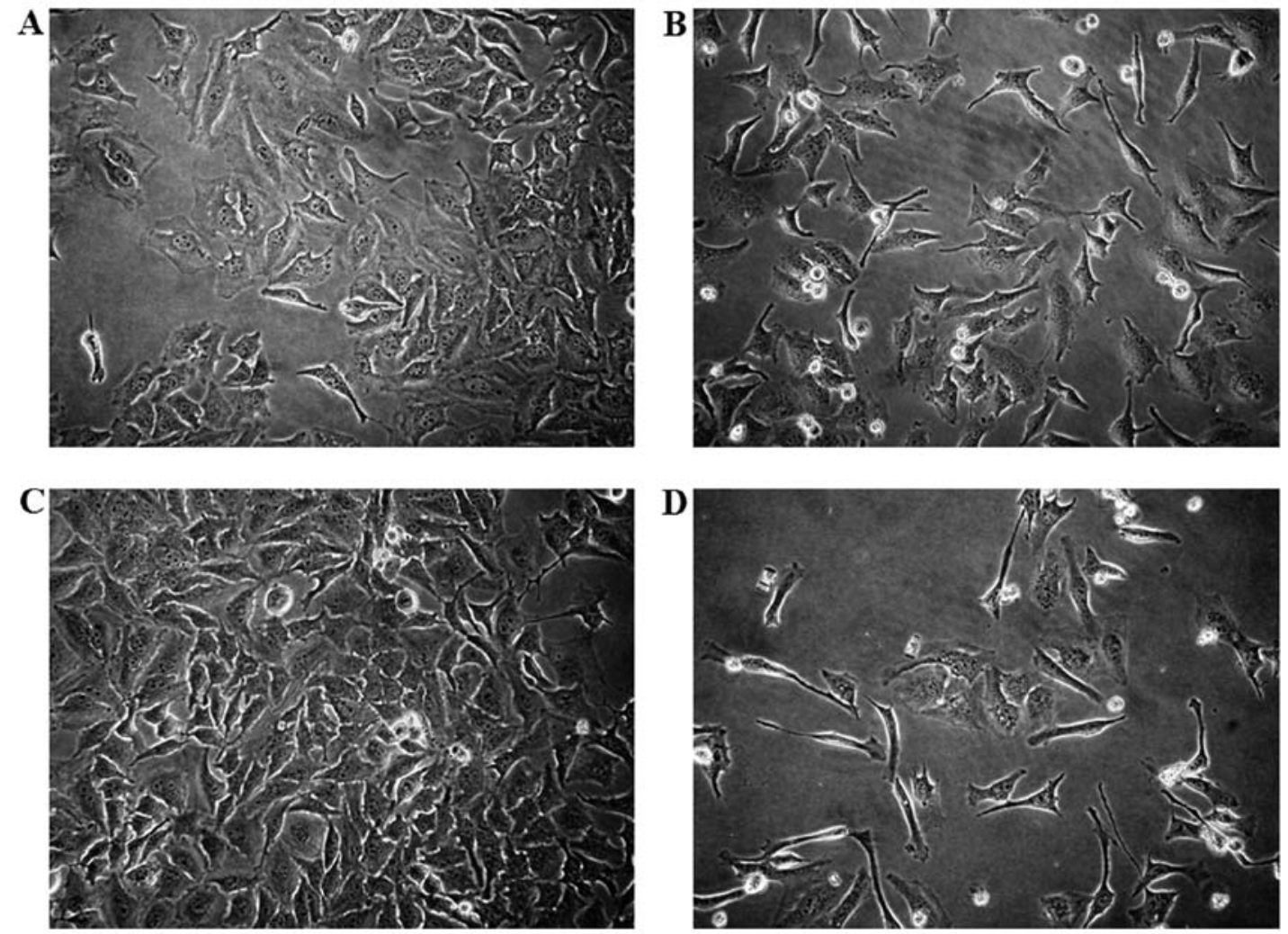

Figure 5. HeLa cell morphological changes by analog 9 treatment. Growth of HeLa cells without analog 9 for (A) 24 and (C) $48 \mathrm{~h}$, respectively. With treatment of $15 \mu \mathrm{M}$ of analog 9, remnant HeLa cells for (B) 24 and (D) $48 \mathrm{~h}$, respectively. Morphological changes of Optic phase-contrast photographs were taken with Nikon ${ }^{\mathrm{TM}}$ Phase Contrast-2, ELWD 0.3 inverted microscope. All the experiments were performed in triplicate and gave similar results.

of apoptotic cells. Morphological changes in the cells treated with various times of analog 9 using light microscopy revealed the presence of apoptosis. Under light microscopy, non-treated analog 9-HeLa cells spread regularly in the culture plates and grew to near confluence (Fig. 5A and C). After treatment with $15 \mu \mathrm{M}$ analog 9 for 24 and $48 \mathrm{~h}$, a significant number of HeLa cells detached from the plate. The detached cells and most of the remnant attached cells showed significant morphological changes that were indicative of apoptosis, e.g., cellular shrinkage and disruption (Fig. 5B and D).

Analog 9 inhibits DNA replication in HeLa cells. To confirm that analog 9 can influence HeLa cells at the DNA level, we examined DNA replication in HeLa cells treated with or without analog 9 by using a $\left[{ }^{3} \mathrm{H}\right]$-thymidine incorporation assay. The reduction of $\left[{ }^{3} \mathrm{H}\right]$-thymidine incorporation in HeLa cells treated with analog 9 indicates that DNA replication was inhibited (Fig. 6) in a time-dependent manner; therefore, we concluded that analog 9 had an effect on DNA replication of the cells.

Analog 9 decreases intracellular $\Delta \Psi_{m}$. The cohesion of mitochondrial membranes in HeLa cells was examined by Rh-123 staining, where a decrease in Rh-123 fluorescence density reflects a decrease in intracellular $\Delta \Psi_{\mathrm{m}}$. The cells were treated with or without analog 9 for 12 and $24 \mathrm{~h}$. Untreated cells had similar fluorescence between 12 and $24 \mathrm{~h}$ (Fig. 7A and C); however, cells treated with analog 9 exhibited a time-dependent decrease in intracellular $\Delta \Psi_{\mathrm{m}}$ (Fig. 7B and D). Fig. 7E shows the data for cells treated with $\mathrm{H}_{2} \mathrm{O}_{2}$, which were used as a positive control to confirm these data.

Analog 9 induces the mitochondria-mediated apoptosis pathway in HeLa cells. Caspases play a central role in apoptosis, once activated, they can activate other procaspases, allowing the initiation of a protease cascade. In order to determine the molecular mechanism of analog 9-induced apoptosis in HeLa cells, we evaluated whether the caspase-dependent signaling pathway and mitochondria-mediated pathway were involved in analog 9-induced apoptosis. HeLa cells were treated with $15 \mu \mathrm{M}$ analog 9 (according to the cytotoxicity data). The members of the Bcl-2 family play essential roles in initiating the mitochondria-mediated pathway (33). Bcl-2 is known as an antiapoptotic protein, and its levels were decreased in cells treated with analog 9 in a time-dependent manner. Conversely, Bax levels were increased in cells treated with analog 9 because it is a proapoptotic protein (Fig. 8A). Change in the levels of $\mathrm{Bcl}-2$ family proteins results in the release of cytochrome $c$ from the mitochondria, which then activates the downstream caspase program (21). When the levels of procaspases decrease, the levels of caspases increase to initiate apoptosis. As shown in Fig. 8A, the levels of procaspase-3 and -9 decreased following treatment with analog 9; therefore, we concluded that the levels of caspase- 3 and -9 were increased by analog 9 . The levels of p53, a tumor suppressor protein, showed a tendency to increase following treatment with analog 9 ; therefore, we concluded that analog 9 suppressed the levels of a tumor growth factor. 


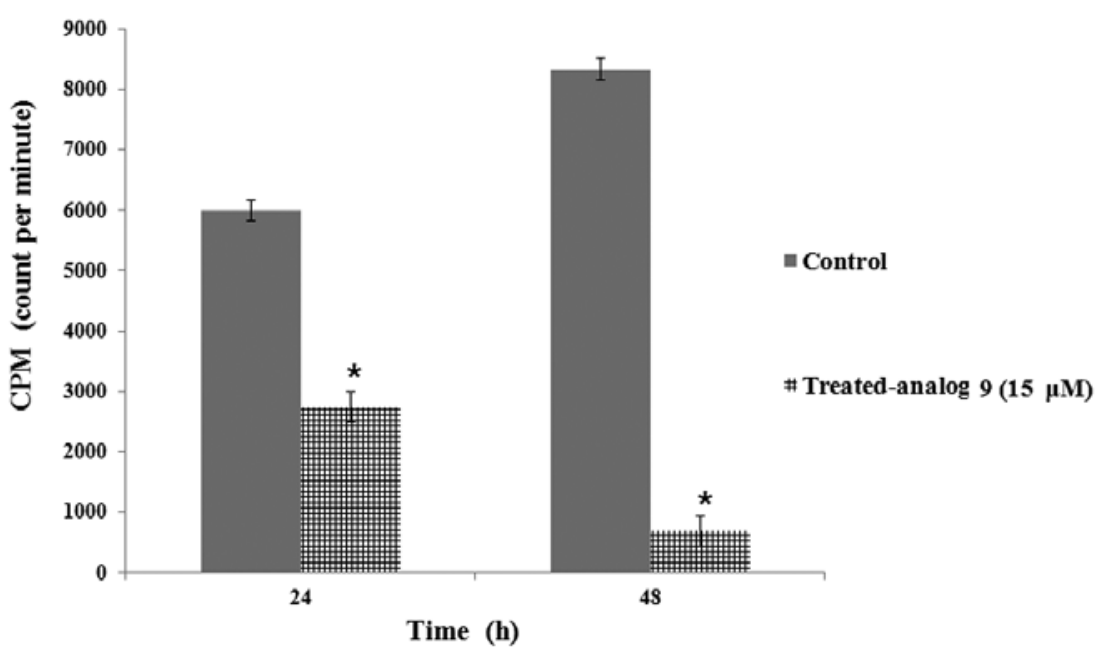

Figure 6. Analog 9 inhibits DNA replication of HeLa. The result of DNA replication in HeLa cells treated with or without analog 9 by $\left[{ }^{3} \mathrm{H}\right]$-thymidine incorporation assay. Results are the mean $\pm \mathrm{SD}, \mathrm{n}=3$. ${ }^{*} \mathrm{P}<0.05$, denotes statistically significant difference vs. the control at the same level.

$\mathbf{A}$

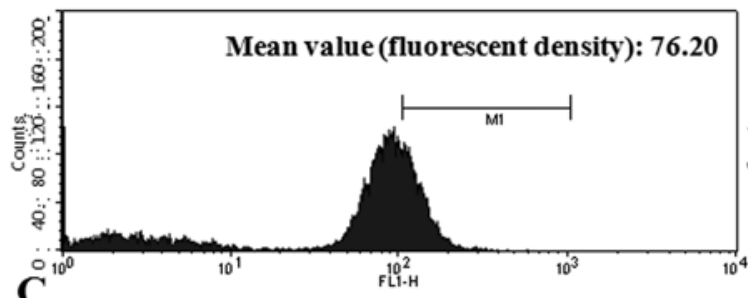

C
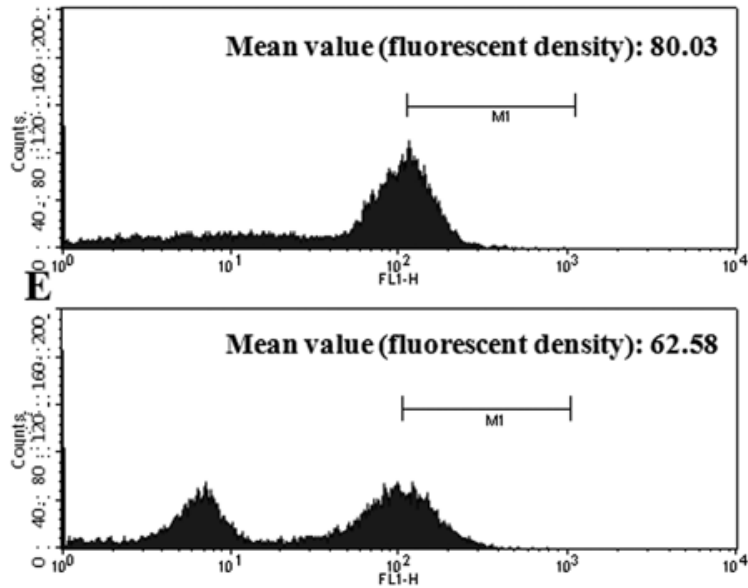

B

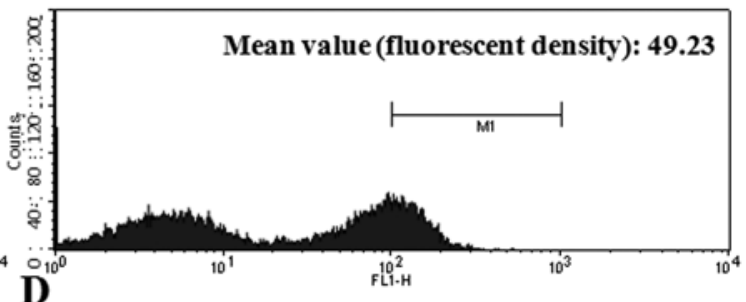

$\stackrel{\circ}{\mathbf{1}^{0}}$

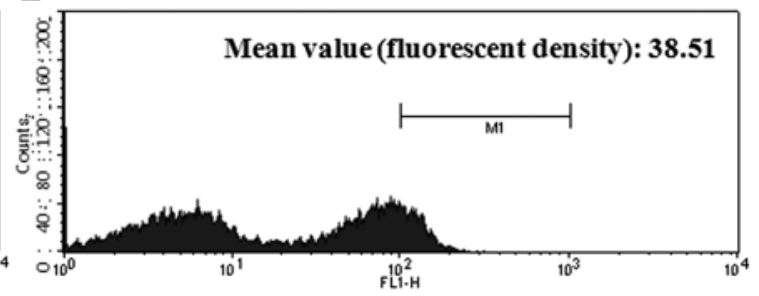

Figure 7. Analog 9 leads to intracellular $\Delta \Psi_{\mathrm{m}}$ decrease. Intracellular mitochondrial membrane potential in HeLa cells was examined by rhodamine 123 staining. Cells were treated with or without analog 9 for 12 and $24 \mathrm{~h}$. Untreated analog 9 cells were measured after (A) 12 and (C) $24 \mathrm{~h}, \mathrm{respectively}$. Treatment with $15 \mu \mathrm{M}$ of analog 9 cells were measured after (B) 12 and (D) $24 \mathrm{~h}$, respectively. (E) $\mathrm{H}_{2} \mathrm{O}_{2}$ was used as a positive agent and measured after 30 min. Results of intracellular $\Delta \Psi_{\mathrm{m}}$ were measured by flow cytometry and analyzed by Cell Quest Pro software (Becton-Dickinson Instruments). All the experiments were performed in triplicate and gave similar results.

Analog 9 has the potential to induce the Fas signaling apoptosis pathway. Caspase- 8 is known for its role in the Fas signaling apoptosis pathway. We analyzed procaspase- 8 to assess whether analog 9 could also trigger the extrinsic pathway. At the first step of this pathway, Fas ligand binds to Fas protein, inducing Fas to decrease procaspase- 8 levels. When the levels of procaspase- 8 are decreased, caspase- 8 levels are increased. Activated caspase- 8 can trigger other caspase proteins, especially caspase-3 (15). Therefore, analog 9 may trigger Fas signaling apoptosis pathway by decreasing the levels of procaspase-8 (Fig. 8B).

\section{Discussion}

Various chemotherapy drugs have been used to treat cancer and many novel compounds are still being developed. Our experimental findings showed that analog 9 induced cytotoxicity in HeLa cells and inhibited their proliferation significantly after 


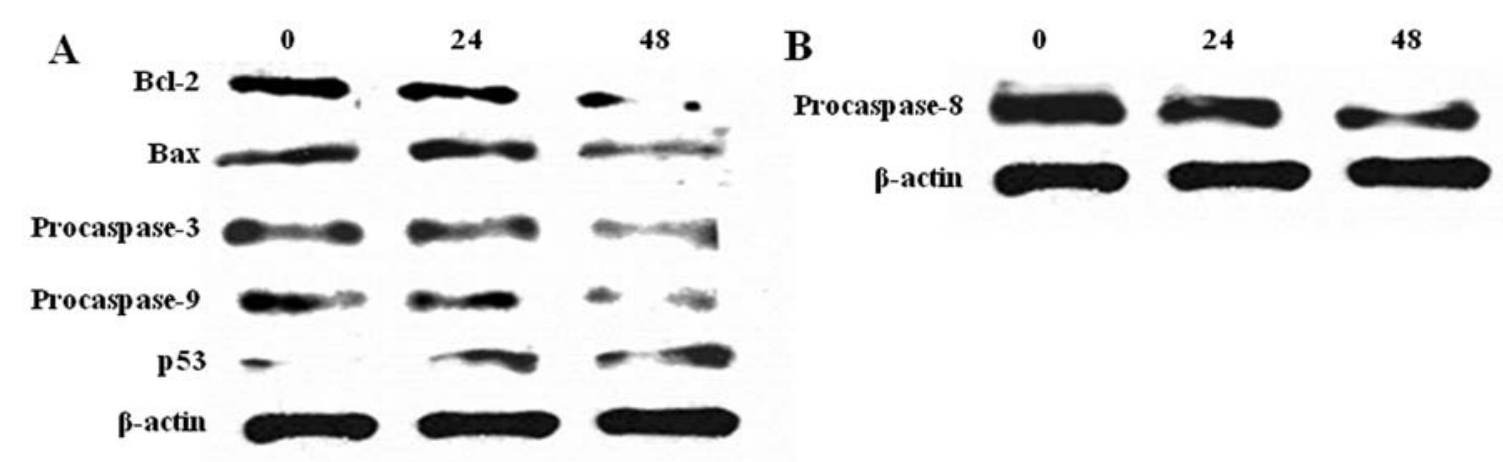

Figure 8. Effects on protein level in analog 9-induced apoptosis. (A) Protein expression levels of Bax, Bcl-2, procaspase-9, procaspase-3 and p53. These protein levels indicate that analog 9 induced the mitochondrial-dependent mediated pathway. (B) The expression level of procaspase-8 is involved in the Fas signaling apoptosis pathway. Expression levels of proteins changed time-dependently. All the experiments were performed in triplicate and gave similar results.

$36 \mathrm{~h}$. As analog 9 had the strongest cytotoxic effect on HeLa cells compared to the other compounds, we suggest that the methoxy group of bispidinone compounds is important for cell cytotoxicity. Analog 9 inhibited the proliferation of HeLa cells at a low concentration; therefore, we wanted to examine the underlying mechanism of cell death.

Many methods have been developed to monitor the different steps of apoptotic pathways $(34,35)$. We initially assessed apoptosis in HeLa cells by observing morphological changes. The abnormal morphology of cells treated with analog 9 showed an apoptotic pattern, including a reduction in the volume, number, and fragmentation of HeLa cells. The Annexin V-FITC/PI double staining assay suggested that analog 9 induced early apoptosis in HeLa cells time-dependently. These data indicated that analog 9 inhibited the proliferation of HeLa cells and induced cytotoxicity by triggering apoptosis. However, the enzyme activity of apoptotic and cell cycle regulators should be characterized to clarify the mechanisms by which analog 9 induced apoptosis. Since the activation and execution of apoptosis are regulated by complex molecular mechanisms, numerous points of interaction exist between the regulatory pathways of the cell cycle and apoptosis (36). We observed the accumulation of HeLa cells at the G1 phase at $24 \mathrm{~h}$ following treatment with analog $9(30,37)$. On the basis of these results, we concluded that analog 9 induced G1 phase arrest.

The $\left[{ }^{3} \mathrm{H}\right]$-thymidine incorporation assay suggested that analog 9 inhibited DNA replication; therefore, we obtained evidence that analog 9 influenced the DNA levels in HeLa cells. Through the process of apoptosis, any cell that is severely damaged beyond the capacity of the DNA repair system or cannot be repaired, is eliminated. Therefore, analog 9 induced DNA strand breaks and inhibited the incorporation of $\left[{ }^{3} \mathrm{H}\right]$-thymidine before any cell cycle change had occurred. In conclusion, this study provides experimental evidence that analog 9 induced apoptosis in HeLa cells that was accompanied by the inhibition of DNA replication.

To identify the underlying apoptotic pathway that was induced by analog 9 , we measured $\Delta \Psi_{\mathrm{m}}$ using Rh-123 staining and western blot analysis. Rh-123 staining indicated that analog 9 disrupted $\Delta \Psi_{\mathrm{m}}$. Western blot analysis was performed to confirm this finding. The Bcl-2 family proteins Bax and Bcl-2 play important roles in initiating the mitochondria-medi-

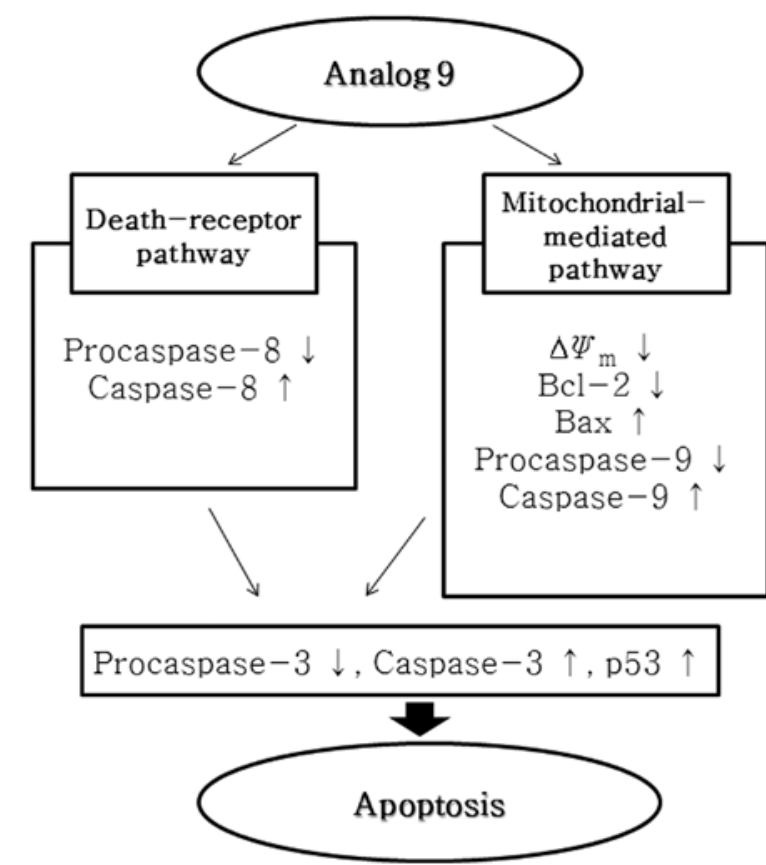

Figure 9. The proposed model of molecular signal pathways in HeLa cells after exposure to analog 9 .

ated apoptotic pathway (33). Proapoptotic Bax translocates to the mitochondria and integrates into the outer mitochondrial membrane, where it promotes the release of cytochrome $c$ into the cytosol. In contrast, antiapoptotic Bcl-2 prevents this process by preserving mitochondrial integrity. Thus, the ratio of Bax to Bcl-2 is crucial to the sustenance of drug-induced apoptosis in the mitochondria-dependent apoptotic pathway (38). A recent study showed that analog 9 upregulated the expression of Bax and downregulated the expression of Bcl-2. The release of mitochondrial cytochrome $c$ facilitates the formation of apoptosome complexes consisting of APAF-1 and caspase-9, which subsequently activate caspases, e.g., caspase-3, resulting in apoptosis (21). In the present study, the activation of caspase- 3 and -9 was detected. In addition, the levels of p53, a tumor suppressor protein, increased significantly. These results showed that analog 9 induced apoptosis via the caspase- and mitochondria-mediated pathways. In 
addition, we suggest the possibility that analog 9 induced the extrinsic apoptotic pathway.

In conclusion, this study provides experimental evidence that analog 9 induces apoptosis in HeLa cells via the mitochondria- and caspase-mediated pathways, and may induce the extrinsic pathway. Analog 9 also inhibits DNA replication in HeLa cells and induces sub-G1 and G1 phase arrest in the HeLa cell cycle. Finally, analog 9 also disrupts $\Delta \Psi_{\mathrm{m}}$ (Fig. 9).

To date, no study has assessed the anticancer activity of bispidinone analogs, and this present study serves as the first attempt to evaluate the action of analog 9 on HeLa cells. These findings show that analog 9 should be studied as an anticancer agent in future research.

\section{Acknowledgements}

This study was supported by the 2013 Inje University research grant.

\section{References}

1. Balaiah V, Jeyaraman R and Chandrasekaran L: Synthesis of 2,6-disubstituted piperidines, oxanes, and thianes. Chem Rev 83: 379, 1983.

2. Vijayakumar V and Sundaravadivelu M: Synthesis and study on 2,4,6,8-tetraaryl-3,7-diazabicyclo[3.3.1]. Magn Reson Chem 43 479-482, 2005

3. Juran S, Walther M, Stephan H, Bergmann R, Steinbach J, Kraus W, Emmerling F and Comba P: Hexadentate bispidine derivatives as versatile bifunctional chelate agents for copper(II) radioisotopes. Bioconjug Chem 20: 347-359, 2009.

4. Joensuu H: Systemic chemotherapy for cancer: from weapon to treatment. Lancet Oncol 9: 304, 2008.

5. Degterev A, Boyce M and Yuan J: A decade of caspases. Oncogene 22: 8543-8567, 2003.

6. Ziegler DS and Kung AL: Therapeutic targeting of apoptosis pathways in cancer. Curr Opin Oncol 20: 97-103, 2008.

7. Kurokawa M and Kornbluth S: Caspases and kinases in a death grip. Cell 138: 838-854, 2009.

8. Desagher S and Martinou JC: Mitochondria as the central control point of apoptosis. Trends Cell Biol 10: 369-377, 2000

9. Cory S and Adams JM: The Bcl-2 family: regulators of the cellular life-or-death switch. Nat Rev Cancer 2: 647-656, 2002.

10. Farrow NS and Brown R: New members of the Bcl-2 family and their protein partners. Curr Opin Genet Develop 6: 45-49, 1996.

11. Yang E, Zha J, Jockel J, Bosie LH, Thompson CB and Korsmeyer SJ: Bad, a heterodimeric partner for Bcl-xL and Bcl-2, displaces bax and promotes cell death. Cell 80: 285-291, 1995.

12. Danial NN and Korsmeyer SJ: Cell death: critical control points. Cell 116: 205-219, 2004.

13. Verhagen AM, Ekert PG, Pakusch M, Silke J, Connolly LM, Reid GE, Moritz RL, Simpson RJ and Vaux DL: Identification of DIABLO, a mammalian protein that promotes apoptosis by binding to and antagonizing IAP proteins. Cell 102: 43-53, 2000.

14. Green DR and Reed JC: Mitochondria and apoptosis. Science 281: 1309-1312, 1998.

15. Kumar S and Vaux DL: Apoptosis. A Cinderella caspase takes center stage. Science 297: 1290-1291, 2002.

16. Jin Z and El-Deiry WS: Overview of cell death signaling pathways. Cancer Biol Ther 4: 139-163, 2005.

17. Liu J, Shen M, Yue Z, Yang Z, Wang M, Li C, Xin C, Wang Y, Mei Q and Wang Z: Triptolide inhibits colon-rectal cancer cells proliferation by induction of G1 phase arrest through upregulation of p21. Phytomedicine 19: 756-762, 2012.
18. Lodish H, Berk A, Zipursky SL, Matsudaria P, Baltimore D and Darnell J: Molecular Cell Biology. 4th edition. W.H. Freeman, New York, NY, 2000.

19. Zhao J, Kang SRM, Zhang X, You S, Park JS, Jung JH and Kim DK: Apoptotic activity of a new jasmonate analogue is associated with its induction of DNA damage. Oncol Rep 24 771-777, 2010.

20. Fisher DE: Apoptosis in cancer therapy: crossing the threshold. Cell 78: 539-542, 1994.

21. Ghobrial IM, Witzig TE and Adjei AA: Targeting apoptosis pathways in cancer therapy. CA Cancer J Clin 55: 178-194, 2005.

22. Tominaga H, Ishiyama M, Ohseto F, Sasamoto K, Hamamoto T, Suzuki K and Watanabe M: A water-soluble tetrazolium salt useful for colorimetric cell viability assay. Anal Commun 36: 47-50, 1999.

23. Zhang X, Zhao Z, Kang SRM, Yi MJ, You S, Shin DS and Kim DK: A novel cromakalim analogue induces cell cycle arrest and apoptosis in human cervical carcinoma HeLa cells through the caspase- and mitochondria-dependent pathway. Int J Oncol 39: 1609-1617, 2011.

24. Lin SY, Liu JD, Chang HC, Yeh SD, Lin CH and Lee WS: Magnolol suppresses proliferation of cultured human colon and liver cancer cells by inhibiting DNA synthesis and activating apoptosis. J Cell Biochem 84: 532-544, 2002.

25. Qi F, Li A, Zhao L, Xu H, Inagaki Y, Wang D, Cui X, Gao B, Kokudo N, Nakata M and Tang W: Cinobufacini, an aqueous extract from Bufo bufo gargarizans Cantor, induces apoptosis through a mitochondria-mediated pathway in human hepatocellular carcinoma cells. J Ethnopharmacol 128: 654-661, 2010.

26. Zhang Y, Ahn EY, Jiang Y, Kim DK, Kang SG, Wu C, Kang SW, Park JS, Son BW and Jung JH: 3-Chloro-2,5dihydroxybenzyl alcohol activates human cervical carcinoma HeLa cell apoptosis by inducing DNA damage. Int J Oncol 31: 1317-1323, 2007.

27. Sánchez I and Dynlacht BD: New insights into cyclins, CDKs, and cell cycle control. Semin Cell Dev Biol 16: 311-321, 2005.

28. Lee S, Christakos S and Small MB: Apoptosis and signal transduction: clues to a molecular mechanism. Curr Opin Cell Biol 5: 286-291, 1993.

29. Dou QP: Putative roles of retinoblastoma protein in apoptosis. Apoptosis 2: 5-18, 1997.

30. Smith DM, Gao G, Zhang X, Wang G and Dou QP: Regulation of tumor cell apoptotic sensitivity during the cell cycle (Review). Int J Mol Med 6: 503-507, 2000.

31. Vermes I, Haanen C, Steffens-Nakken H and Reutelingsperger C: A novel assay for apoptosis flow cytometric detection of phosphatidylserine expression on early apoptotic cells using fluorescein labelled Annexin V. J Immunol Methods 184: 39-51, 1995.

32. Del Bino G, Darzynkiewicz Z, Degraef C, Mosselmans R, Fokan D and Galand P: Comparison of methods based on annexin-V binding, DNA content or TUNEL for evaluating cell death in HL-60 and adherent MCF-7 cells. Cell Prolif 32: 25-37, 1999.

33. Gross A, McDonnell JM and Korsmeyer SJ: BCL-2 family members and the mitochondria in apoptosis. Genes Dev 13: 1899-1911, 1999.

34. Kiechle FL and Zhang X: Apoptosis: biochemical aspects and clinical implications. Clin Chim Acta 326: 27-45, 2002.

35. Otsuki Y, Li Z and Shibata MA: Apoptotic detection methods from morphology to gene. Prog Histochem Cytochem 38: 275-339, 2003

36. Evan GI and Vousden KH: Proliferation, cell cycle and apoptosis in cancer. Nature 411: 342-348, 2001.

37. Orren DK, Petersen LN and Bohr VA: Persistent DNA damage inhibits S-phase and G2 progression and results in apoptosis. Mol Biol Cell 8: 1129-1142, 1997.

38. Qi F, Inagaki Y, Gao B, Cui X, Xu H, Kokudo N, Li A and Tang W: Bufalin and cinobufagin induce apoptosis of human hepatocellular carcinoma cells via Fas- and mitochondriamediated pathways. Cancer Sci 102: 951-958, 2011. 